\title{
Formation Mechanism of Reduction Spheroids with Dark Cores in Cretaceous Red Beds in Jiaolai Basin, China
}

\author{
Yu Yang1, Wenzhao Fu${ }^{1}$, Jifeng $\mathrm{Yu}^{2}$, Zhenguo Ning ${ }^{3}$, Jianjun Cui ${ }^{4,5}$, Qing $\mathrm{Li}^{6}$, Xuelei Wang1, \\ Xizhun Zhuo ${ }^{1}$ \\ ${ }^{1}$ Liaoning Technical University, Fuxin, China \\ ${ }^{2}$ Shandong University of Science and Technology, Qingdao, China \\ ${ }^{3}$ Shandong Institute of Geological Survey, Jinan, China \\ ${ }^{4}$ Institute of Geomechanics, Chinese Academy of Geological Sciences, Beijing, China \\ ${ }^{5}$ Laboratory of Paleomagnetism and Tectonic Reconstruction of Ministry of Natural Resources, Institute of Geomechanics, \\ Chinese Academy of Geological Sciences, Beijing, China \\ ${ }^{6}$ Bureau of Geophysical Prospecting INC., China National Petroleum Corporation, Zhuozhou, China \\ Email: *fwzh04@163.com
}

How to cite this paper: Yang, Y., Fu, W.Z. Yu, J.F., Ning, Z.G., Cui, J.J., Li, Q., Wang, X.L. and Zhuo, X.Z. (2019) Formation Mechanism of Reduction Spheroids with Dark Cores in Cretaceous Red Beds in Jiaolai Basin, China. Open Journal of $\mathrm{Ge}$ ology, 9, 707-710.

https://doi.org/10.4236/ojg.2019.910081

Received: August 17, 2019

Accepted: September 22, 2019

Published: September 25, 2019

Copyright (c) 2019 by author(s) and Scientific Research Publishing Inc. This work is licensed under the Creative Commons Attribution International License (CC BY 4.0).

\begin{abstract}
Red beds are not entirely red sometimes, in which grey-green spheroids or irregular spots can be found. However, the formation mechanism of grey-green spheroids or irregular spots in red beds is not clear so far. Samples taken from well JK1 in Jiaozhou area of Jiaolai Basin displayed that the reduction spheroids have more Vanadium $(\mathrm{V})$ element, less $\mathrm{TFe}_{3} \mathrm{O}_{4}$ and Lead $(\mathrm{Pb})$ element, almost the same content of other elements such as $\mathrm{FeO}$ and so on, comparing the red parts of the samples. The existence of organisms can explain the existence of green reductive spheres in the red beds formed under the oxidation environment.
\end{abstract}

\section{Keywords}

Red Beds, Reduction Spheroids, Formation Mechanism, Jiaolai Basin, Eastern China

\section{Introduction}

Color is one of the most important physical indicators of sedimentary rocks, which can be used for dividing rock types, stratigraphic division, analyzing palaeogeographic climate and sedimentary redox state and so on. It also has high landscape values. Red beds have attracted many scholars' attention for the bright color. 
Red beds are not entirely red sometimes, in which grey-green spheroids or irregular spots can be found. Green reduction spheroids with dark cores containing enrichments of tellurium ( $\mathrm{Te}$ ) and selemium are found in red beds sediments from Mesoproterozoic successions [1]. There are similar geological phenomena in the Baikouquan Formation of the Mahu depression [2], the Lower Cretaceous Liwaxia Formation in Liupanshan [3], the Cretaceous Heshangpu Formation in Kongtongshan [4], and the Hongtuya Formation of Jiaolai Basin in China. Although the different explanations are given by the researchers, there is a conclusion that red represents the oxidizing environment while green represents the reducing environment. Samples from red beds in Jiaolai Basin were studied in order to ascertain formation mechanism of reduction spheroids in red beds.

\section{Materials and Methods}

Samples were taken from well JK1 in Jiaozhou area of Jiaolai Basin, which is scientific drilling with $664.7 \mathrm{~m}$ depth carried out by Shandong Institute of Geological Survey and Institute of Geology, Chinese Academy of Geological Sciences. K/Pg boundary has been emphatically studied and was determined at $537.4 \mathrm{~m}$ depth in JK1 [5]. One sample in red beds with $593.2 \mathrm{~m}$ depth has reduction spheroids with dark core clearly (Figure 1). The samples are observed under stereoscope and polarizing microscope, and analyzed the content of major and trace element in Analytical Laboratory Beijing Research Institute of Uranium Geology.

\section{Result}

Either red or green of the samples contacting mutative with no transitional color are original color instead of secondary color under the microscope, because the chromogenic minerals exist in the form of cements. The debris grains are mainly quartz. The red parts of the sample have almost same minerals with the reduction spheroids except the chromogenic minerals, which are confirmed by the microscopic photographs and XRD analysis results. The reduction spheroids have more Vanadium (V) element, less $\mathrm{TFe}_{3} \mathrm{O}_{4}$ and Lead $(\mathrm{Pb})$ element, almost the same content of other elements such as $\mathrm{FeO}$ and so on, comparing the red parts of the samples, according to the analysis results of principal and trace elements. Further, the dark cores have obvious abundant $\mathrm{V}$ element comparing the rest area of reduction spheroids due to the electron probe analysis.

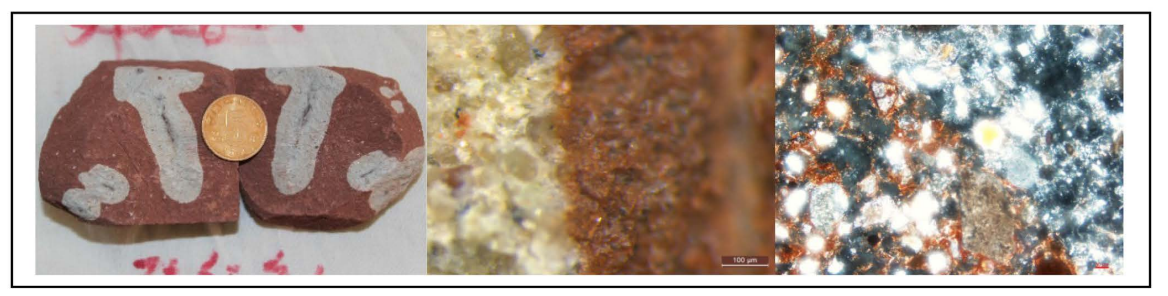

Figure 1. Different scale pictures of sample with $593.2 \mathrm{~m}$ depth from well JK1. 


\section{Discussion}

Oxygen penetration into the subsurface, where spheroids develop, would have been relatively shallow, promoting redox boundaries [1]. Formation mechanism of reduction spheroids in red beds from the Baikouquan Formation of Mahu depression is that iron oxide is reduced by osmotic water, leaving a faded light green-gray spot after reduction [2]. Green interbeds in red beds from the Liwaxia Formation of Liupanshan called zebra mudstones, reflect the changes of redox environment. Taken together, reduction spheroids in red beds reflect the limited reduction in oxidizing environment. What is most important is that whether reduction or oxidization happened first.

The samples from red beds of Jiaolai Basin indicated that the distribution of reducing spheres in red beds is irregular, which illustrated that osmotic water generating green reduction spheroids is small probability event. Oxygen penetration into the subsurface, where spheroids develop, can't explain the large scales of red beds ( $>2000 \mathrm{~m}$ thick). However, abundant Vanadium which was an element of atypical biological significance has been found in sea water, sea urchins and other marine organisms, magnetite, asphalt minerals and coal ash [6] [7] [8]. In this way, it was inferred that reduction spheroids with dark cores in red beds are symbols of biological remains or activities, in other words, the dark cores may be fossils. However, we can't decide the biological species so far.

\section{Acknowledgements}

This research was financially supported by the Liaoning Provincial Department of Education Youth Foundation (LJ2017QL027), National Science Foundation of China (41472092). We sincerely appreciate Engineer XU Kemin who is in Shandong Institute of Geological Survey for field sampling. This is a contribution to UNESCO/IUGS/IGCP 679 project.

\section{Conflicts of Interest}

The authors declare no conflicts of interest regarding the publication of this paper.

\section{References}

[1] Parnell, J., Spinks, S. and Brolly, C. (2018) Tellurium and Selenium in Mesoproterozoic Red Beds. Precambrian Research, 305, 145-150.

[2] Ding, Y. and Zhang, C.M. (2015) The Relationship between the Color of Sedimentary Rocks and Diagenesis-Taking Baikouquan Formation in Mahu Depression as an Example. Summary of Sedimentology and Non-Conventional Resources Papers of the National Sedimentology Congress.

[3] Zhang, W.F., Dai, S. and Liu, H.J. (2012) The Geochemistry of the Early Cretaceous Red and Green Mudstones, Liupanshan Group, Liupanshan Area and Its Implications on the Climate. Advances in Earth Science, 27, 1236-1244.

[4] Tan, Z.D., Liang, S.Y. and Zhou, Z.Q. (2018) Relationship of Mudstone Color and Fractal Dimension Based on SEM Image: A Case Stuty of the Cretaceous Zebra 
Mudstone in Kongtong Mountain National Geopark. Geological Survey and Research, 41, 153-160

[5] Xu, K.M., Kuang, H.W. and Qin, J. (2017) New Discovery of Terrestrial K-Pg Boundary from Jiaolai Basin of Shandong Province. Geology in China, 44, 194-195.

[6] Wever, R., de Boer, E., Plat, H. and Krenn, B.E. (1987) Vanadium-An Element Involved in the Biosynthesis of Halogenated Compounds and Nitrogen Fixation. FEBS Letters, 216, 1-3. https://doi.org/10.1016/0014-5793(87)80744-5

[7] Mukherjee, B., Patra, B. and Mahapatra, S. (2004) Vanadium-An Element of Atypical Biological Significance. Toxicology Letters, 150, 135-143.

[8] Aihemati, A., Jiang, J. and Gao, Y. (2019) The Effect of Vanadium on Essential Element Uptake of Setaria viridis Seedlings. Journal of Environmental Management, 237, 399-407. https://doi.org/10.1016/j.jenvman.2019.02.054 